\title{
Rancang Bangun Buka Tutup Pintu Pagar Rumah Menggunakan Remote Control Wireless Rf315
}

\author{
Fitri \\ Teknik Informatika STMIK Atma Luhur Pangkalpinang \\ J1. Jend. Sudirman, Selindung, Pangkalpinang \\ Kepulauan Bangka Belitung \\ $\underline{\text { muksen.tjioe@gmail.com }}$
}

\author{
Yohanes Setiawan \\ STMIK Atma Luhur \\ Jl. Jend. Sudirman, Selindung, Pangkalpinang \\ Kepulauan Bangka Belitung \\ ysetiawan@atmaluhur.ac.id
}

\begin{abstract}
Abstrak - Tujuan dari penulisan penulisan ini adalah untuk untuk meningkatkan efisiensi dan efektifitas proses buka tutup pintu pagar rumah. Metode penelitian yang digunakan adalah dengan metode studi pustaka, analisis, perancangan dan implementasi. Hasil yang dicapai adalah meningkatnya efisiensi dan efektifitas proses buka tutup pintu pagar. Pengguna dari pengaplikasian rancang bangun aplikasi buka tutup pintu pagar rumah otomatis menggunakan remote control wireless RF315 akan merasa efisiensi dan efektifitas dari penerapannya. Prinsip kerja rancang bangun aplikasi buka tutup pintu pagar rumah otomatis menggunakan remote control wireless RF315 pada dasarnya adalah pengguna harus memiliki remote control wireless RF315, dilakukan inisilisasi ke arduino setiap tombolnya dan jika tombol pada remote di tekan maka akan dikirimkan perintah secara nirkabel ke arduino sebagai input value, lalu arduino akan mentransformasi perintah tersebut agar dapat di baca oleh easy driver, easy driver berfungai untuk meneruskan perintah ke motor stepper untuk melakukan aksi tarik atau dorong pada pagar. Kesimpulan yang didapat adalah setelah rancang bangun aplikasi buka tutup pintu pagar rumah otomatis menggunakan remote control wireless RF315 terdapat proses pengiriman perintah dari remote ke arduino lalu diteruskan ke motor pernggerak melalui driver.
\end{abstract}

Kata Kunci :Remotei, Mikrokontroler, Pagar, Motor.

\section{Pendahuluan}

Selama ini secara umum proses buka tutup pagar dilakukan secara manual kurang efektif misalnya penghuni rumah harus turun langsung membuka pintu pagar secara manual dengan cara menarik atau mendorongnya dengan tangan, padahal untuk kondisi tertentu seperti pada saat hujan melakukan buka tutup pagar rumah dengan manual akan repot apalagi penghuni rumah mewah yang ingin semua serba praktis. Adapun tujuan penelitian ini adalah untuk meningkatkan efisiensi dan efektifitas proses buka tutup pintu pagar, dimana proses untuk membuka dan menutup pagar dapat dilakukan secara praktis dengan menggunakan remote control wireless RF 315 yang bisa berupa gantungan kunci kendaraan. Proses buka tutup pintu akan lebih cepat karena pengemudi tidak perlu melakukan aksi dorong buka pagar ataupun tutup pagar. Setelah melihat latar permasalahan yang sudah diuraikan maka penulis ingin membuat rancang bangun yang dapat memecahkan permasalahan yang ada yaitu dengan membuat " Rancang Bangun Aplikasi Buka dan Tutup Pintu Pagar Rumah Otomatis Menggunakan Remote Control Wireless RF 315"

\section{TINJAUAN PUSTAKA}

\section{A. Tinjauan Studi}

Penelitian yang dilakukan oleh A.Ejah Umraeni Salam $d k k$ (2013:5) dengan judul Sistem Kendali Jarak Jauh Pintu Gerbang Otomatis, hasil penelitian dari Fakultas Teknik Universitas Hasanuddin. Sistem yang di rancang memanfaat kan bel rumah sebagai alat control kendali dari gerbang rumah dapat berjalan dengan efektif, akan tetapi tidak efisien karena memiliki jarak kendali pintu rumah yang terbatas[1]. Penelitian yang dilakukan oleh Imam Rokani (2009:4) Pengendali Gerbang Pagar dengan Pemanggil Handphone dan Keypad, hasil penelitian dari Universitas Muhammadiyah Surakarta. Sistem ini memanfaatkan jaringan handphone untuk mengendalikan buka tutup pintu gerbang, dapat berjalan dengan efektif, akan tetapi tidak efisien karena sewaktu-waktu kehilangan jaringan saluran handphone, maka pengguna harus melakukan buka tutup gerbang secara manual dengan menggunakan tenaga manusia[2]. 


\section{Metode Penelitian}

\section{A. Metode Pengumpulan Data}

\section{1) Studi Pustaka (Literatur)}

Yaitu pada tahap ini dilakukan untuk mengambil beberapa data yang berasal dari berbagai sumber seperti buku, jurnal ilmiah, skripsi dan internet dimana isi dari sumber-sumber tersebut dijadikan suatu referensi dan acuan dalam penulisan laporan penelitian ini.

\section{B. Analisa Sistem}

asdasdsnfskenfcksdfnskfsfssmdfsopwp yang berasal dari berbagai sumber seperti buku, jurnal ilmiah, skripsi dan internet dimana:

\section{1) Analisis Masalah}

Pada tahap ini dilakukan untuk mengetahui masalah yang sedang terjadi pada sistem lama atau sistem yang sedang berjalan.

\section{2) Analisis Kebutuhan}

Pada analisis kebutuhan dilakukan agar dapat mengetahui kebutuhan perangkat keras dan perangkat lunak yang digunakan

\section{3) Analisis Kelayakan}

Berdasarkan pada tahap analisis kebutuhan bahwa pada tahap ini menjelaskan apakah sistem yang dibuat layak atau tidak untuk dilanjutkan, baik dari segi kelayakan teknologi maupun dari segi operasional.

\section{4) Analisis Sistem Berjalan}

Pada tahap ini dilakukan agar dapat mengetahui sistem atau proses yang sedang berjalan sekarang, digambarkan dalam activity diagram.

\section{Perancangan Sistem}

Perancangan sistem adalah merancang suatu sistem secara rinci berdasarkan hasil analisis pada sistem yang ada, agar menghasilkan model baru yang diusulkan. Perancangan sistem dilakukan dengan tahap sebagai berikut:

1) Perancangan perangkat keras

Perancangan perangkat keras merupakan skematika alat yang digunakan untuk membangun prototype alat.

\section{Implementasi}

Pada tahap implementasi ini merupakan suatu proses pemaparan hasil dari instalasi perangkat keras, langkahlangkah instalasi perangkat lunak, tampilan layar dan pengujian. Pada tahap pengujian dilakukan uji coba terhadap aplikasi. Kemudian hasil dari uji coba tersebut dievaluasi. Apabila terdapat kesalahan atau kekurangan pada aplikasi tersebut, maka dapat dilakukan perbaikan yang diperlukan.

\section{HASIl DAN PEMBAHASAN}

\section{A. Analisa Kelayakan Sistem}

Analisis kelayakan sistem dapat dilihat pada Tabel 1.

Tabel 1 Analisis Kelayakan Sistem

\begin{tabular}{|c|l|c|c|}
\hline No. & \multicolumn{1}{|c|}{ Item Penilaian } & $\begin{array}{c}\text { Penilaian } \\
\text { Kelayakan }\end{array}$ & Keterangan \\
\hline 1. & Teknologi Mikrokontroler & Ada & Oke \\
\hline 2. & Teknologi wireless & Ada & Oke \\
\hline
\end{tabular}

\section{B. Analisa Kebutuhan Perangkat Lunak}

Analisis kebutuhan perangakat keras yang digunakan pada rancang bangun ini untuk dapat lebih jelas di lihat pada Tabel 2.

Tabel 2 Daftar Perangkat Keras

\begin{tabular}{|c|l|l|l|}
\hline No & Perangkat Keras & Unit & Keterangan \\
\hline 1. & Arduino Uno & 1 & Arduino UNO Atmega 328 \\
\hline 2. & Easy Driver & 1 & Pengontrol motor stepper \\
\hline 3. & Motor Stepper & 1 & Penggerak gerbang \\
\hline 4. & Remote RF 315 & 1 & Pengontrol buka tutup pagar \\
\hline
\end{tabular}

\section{Analisa Kebutuhan Perangkat Lunak}

Analisis kebutuhan perangkat lunak untuk lebih jelas dapat lebih jelas lihat Tabel 3.

Tabel 3 Daftar Perangkat Lunak

\begin{tabular}{|c|l|l|}
\hline No & Perangkat Lunak & Keterangan \\
\hline 1. & Sistem Operasi & Windows 7 Profesional \\
\hline 2. & Aplikasi Bahasa C & Arduino Software \\
\hline
\end{tabular}

\section{Analisa Rancang Bangun Aplikasi}

Analisis berjalan yang digunakan pada rancang bangun ini akan lebih mudah dijelaskan menggunakan activity diagram. Untuk lebih jelas dapat dilihat pada Gambar 1.

\section{E. Perancangan Sistem Kerja}

Perancangan sistem kerja pada rancang bangun ini dijelaskan menggunakan 3diagram yaitu deployment diagram, komponen diagram dan flowchart. Deployment diagram dapat dilihat pada Gambar 2. Untuk komponen diagram dapat dilihat pada Gambar 3 dan Gambar 4. Adapun perancangan sistem menggunakan flowchart dapat dilihat pada Gambar 5 


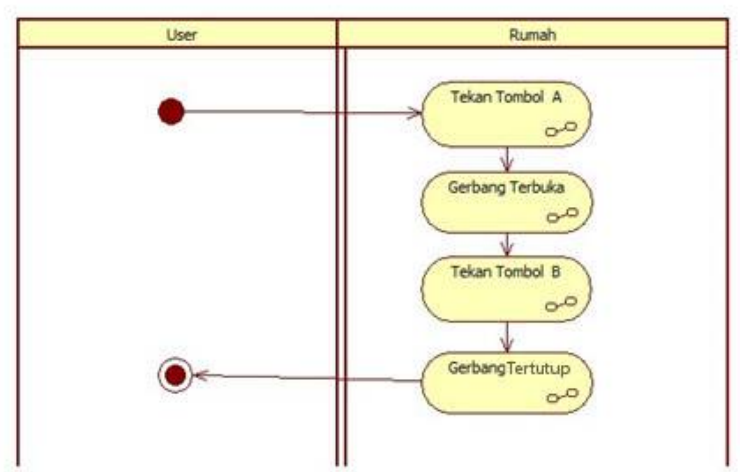

Gambar 1 Activity Diagram

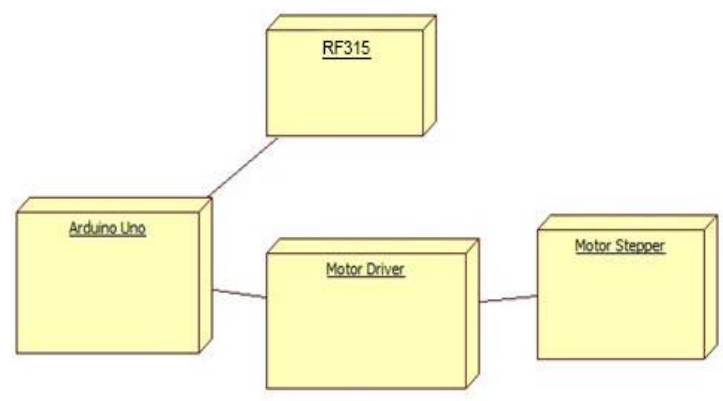

Gambar 2 Deployment Diagram

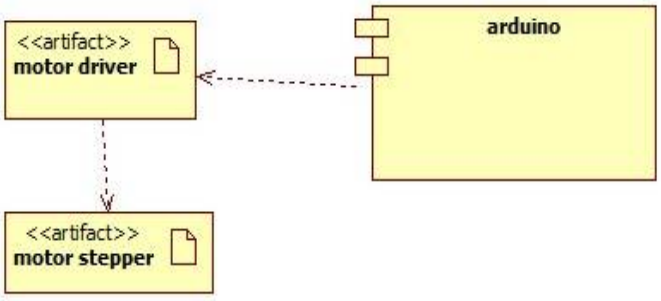

Gambar 3 Komponen Diagram Motor Stepper

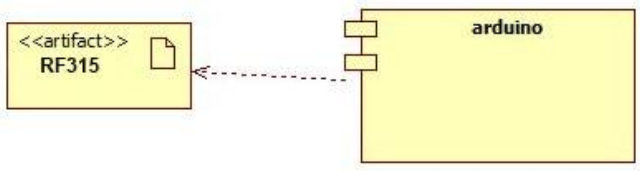

Gambar 4 Komponen Diagram Remote RF 315

\section{F. Interface Perangkat Lunak}

IDE adalah sebuah software untuk menulis program, mengompilasi menjadi kode biner dan meng-upload ke dalam memory mikrokontroler. Lingkungan open-source Arduino memudahkan untuk menulis kode dan meng-upload ke board Arduino. Ini berjalan pada Windows, Mac OS X, dan Linux
Jurnal SISFOKOM, Volume 04, Nomor 02, September 2015

menggununakan Arduino Software, daapat dilihat pada Gambar 6.

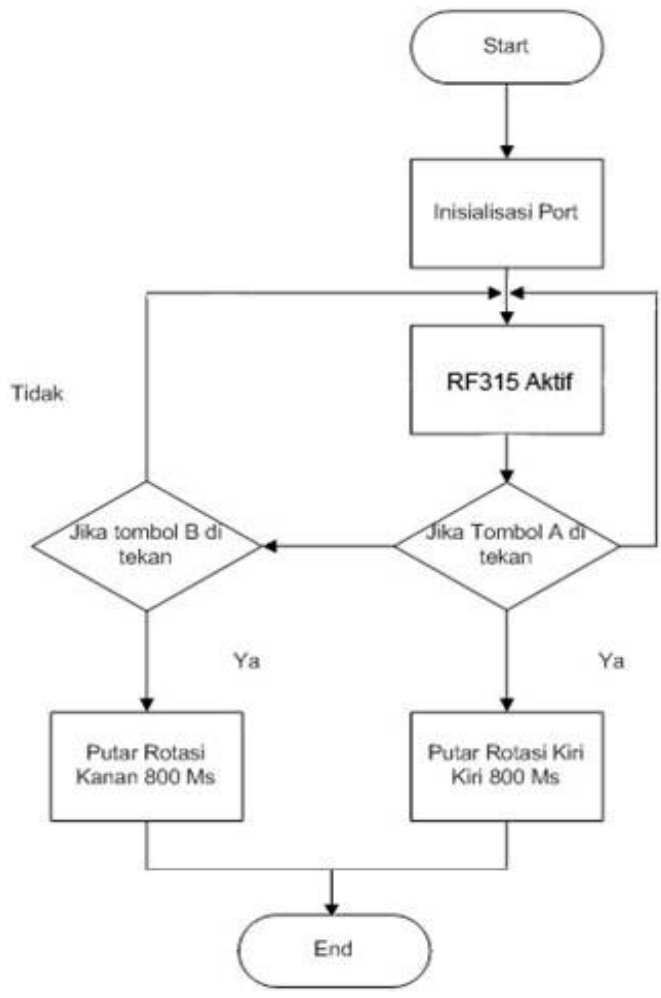

Tidak

Gambar 5 Flowchart

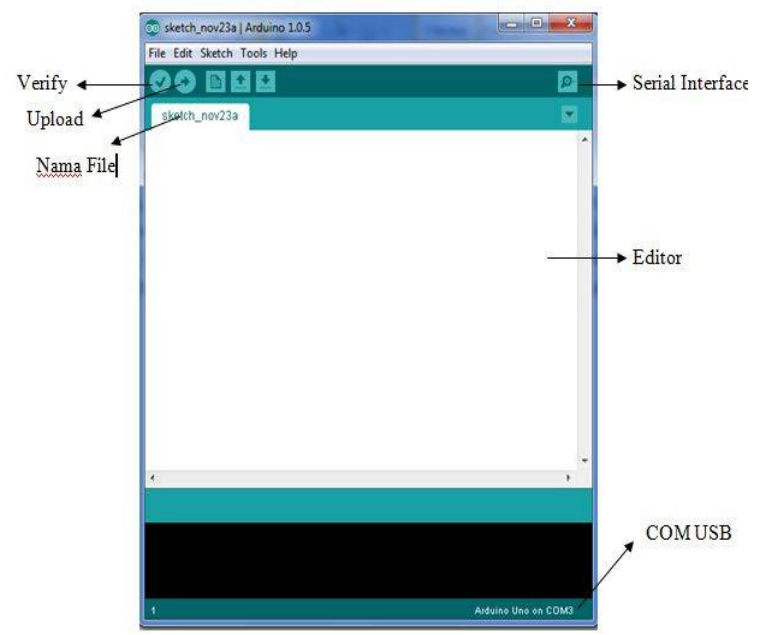

Gambar 6 Interface Perangkat Lunak Arduino Uno

\section{G. Rangkaian Keseluruhan}

Rangkaian keseluruhan dari penelitiannya yaitu dapat dilihat pada Gambar 7. 


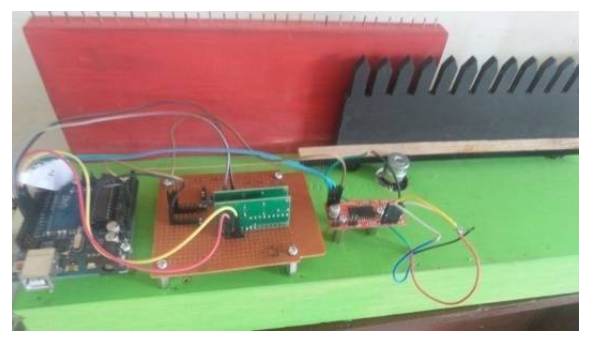

Gambar 7 Rangkaian Terpasang Secara Keseluruhan

\section{H. Algoritma Pemrograman}

Algoritma pada cara kerja rancang bangun ini dapat dijelaskan seperti pada Gambar 8.

\begin{tabular}{|ll|}
\hline 1 & Inisialisasi pin \\
2 & RF 315 aktif \\
3 & Aktifkan motor driver \\
4 & If tombol A high \\
5 & Putar rotasi kiri $800 \mathrm{Ms}$ \\
7 & Else \\
8 & Aktifkan motor \\
9 & If tombol B high \\
10 & Selesai rotasi kanan $800 \mathrm{Ms}$ \\
\hline
\end{tabular}

Gambar 8 Algoritma

\section{Pengujian}

Adapun butir pengujian yang akan dilakukan dijelaskan pada Tabel 4 dan Pengujian Blacbox dijelaskan pada Tabel 5 dan Tabel 6.

\begin{tabular}{|c|c|c|}
\hline Kelas Uji & Butir Uji & $\begin{array}{c}\text { Jenis } \\
\text { Pengujian }\end{array}$ \\
\hline Connect & Connect & Blackbox \\
\hline $\begin{array}{c}\text { Driver Motor } \\
\text { Stepper }\end{array}$ & $\begin{array}{c}\text { Mengendalikan } \\
\text { pergerakan pagar untuk } \\
\text { membuka dan menutup }\end{array}$ & Blackbox \\
\hline
\end{tabular}

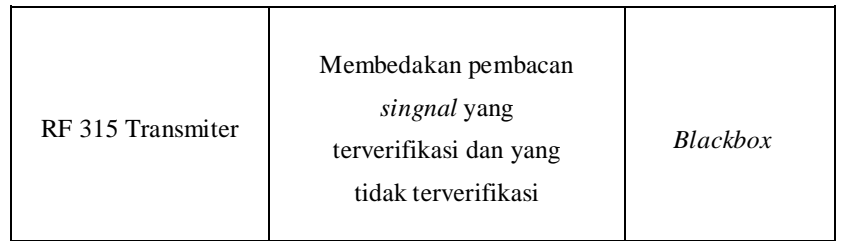

Tabel 5 Hasil Pengujian Motor Stepper

\begin{tabular}{|c|c|c|c|c|}
\hline No & $\begin{array}{r}\text { Ketika } \\
\text { tombol } \\
\text { di tekan }\end{array}$ & $\begin{array}{c}\text { Yang di } \\
\text { harapkan }\end{array}$ & Pengamatan & Kesimpulan \\
\hline 1 & Button A & Motor & Gerbang terbuka & Valid \\
& & stepper & & \\
& & berputar & & \\
& & 800 ms ke & & \\
& & kanan & & \\
\hline 2 & Button B & Motor & Gerbang tertutup & \\
& & stepper & & \\
& & berputar & & \\
& & 800 ms ke & & \\
& & kiri & & \\
\hline
\end{tabular}

Tabel 6 Hasil Pengujian Remote RF 315

\begin{tabular}{|c|c|c|c|c|}
\hline No & Jarak atau & $\begin{array}{c}\text { Yang di } \\
\text { harapakan }\end{array}$ & $\begin{array}{c}\text { Hasil } \\
\text { pengujian }\end{array}$ & Kesimpulan \\
\hline 1 & $0-1 \mathrm{~m}$ & $\begin{array}{l}\text { Respon } \\
\text { diterima }\end{array}$ & Sesuai & Valid \\
\hline 2 & $10-20 \mathrm{~m}$ & $\begin{array}{r}\text { Respon } \\
\text { diterima }\end{array}$ & Sesuai & Valid \\
\hline 3 & $20-40 m$ & Respon diterima & Sesuai & Valid \\
\hline 4 & $50-100 \mathrm{~m}$ & $\begin{array}{c}\text { Tidak bisa } \\
\text {,menerima } \\
\text { respon }\end{array}$ & Sesuai & Valid \\
\hline
\end{tabular}

\section{Penutup}

Kesimpulan yang dapat diambil dari penelitian ini adalah sebagai berikut :

1. Rancang Bangun ini dibuat menggunakan papan mikrokontroller arduino yang dihubungkan dengan remote control wireless RF315 sebagai media input nya. Remote control wireless RF315 ini berfungsi mengirim gelombang elektromagnetik ke motor driver dan diteruskan ke motor stepper. Dengan menggunakan rangkaian ini, maka dapat membuka dan menutup pintu pagar rumah secara otomatis secara efektif dan efisien.

2. Rancang Bangun ini menjadi solusi dari permasalahan yang ada yaitu harus membuka dan 
menutup pintu pagar secara manual atau tenaga manusia karena dikendalikan menggunakan remote control yang berbentuk gantungan kunci.

\section{DAFTAR PUSTAKA}

[1] Salam, A.Ejah Umraeni dkk. Sistem Pengendali Jarak Jauh Pintu Gerbang Otomatis. Makassar, 2013

[2] Rokani, Imam. Pengendali Gerbang Pagar Dengan Pemanggil Handphone dan Keypad . Surakarta, 2009.

[3] Jogiyanto, Hartono. Analisis \& Design Sistem Informasi Pendekatan Terstruktur Teori dan Praktek Aplikasi Bisnis. Yogyakarta, 2005.

[4] Sumardi. MIKROKONTROLLER Belajar AVR Mulai dari Nol. Ruko Jambusari Yogyakarta 55283. Yogyakarta : GRAHA ILMU, 2013

[5] Syahwil, Mohammad.. Panduan Mudah Simulasi \& Praktek Mikrokontroler Arduino", Yogyakarta, 2013

[6] Kusuma, Hendra.. Rancang Bangun Pengendalian Komunikasi Serial Modem Menggunakan Mikrokontroler Sebagai Alat Kontrol Jarak Lampu Penerangan. Skripsi. STMIK Atma Luhur. Pangkalpinang, 2013.

[7] Adelia dan Jimmy Setiawan. Implementasi Customer Relationship Management (CRM) pada Sistem Reservasi Hotel berbasis website dan Desktop. Jurnal Sistem Informasi, vol 6.113-126, 2011

[8] Rizky, Soetam. 2011. Konsep Dasar Rekayasa Perangkat Lunak. Jakarta : Prestasi Pustaka.

[9] Motor DC. http://electrical-icezz.blogspot.co.id. Diakses tanggal 15 Juni 2016 Pukul 16.24

[10] Motor Stepper. http://bukan-sekedar-tahu.blogspot.co.id. Diakses tanggal 15 Juni 2016 Pukul 16.38

[11] Motor Servo. http://d4ea.blogspot.co.id. Diakses tanggal 15 Juni 2016 Pukul 17.23
[12] Remote RF 315. https://www.tokopedia.com/nara-elektronik/remotecontrol-wireless-rf-4-channel-tombol-receiver-arduino-2262-2272. Diakses tanggal 16 Juni 2016 Pukul 14.03

[13] Activity Diagram. http://www.id.wikipedia.org. Diakses tanggal 16 Juni 2016 Pukul 14.45

[14] Deployment Diagram. http://www.bangpahmi.com. Diakses tanggal 16 Juni 2016 Pukul 14.58

[15] Algoritma. http://dsmlmdblog.blogspot.co.id. Diakses tanggal 16 Juni 2016 Pukul 15.08

[16] Pseudo Code. http://www.id.wikipedia.org. Diakses tanggal 16 Juni 2016 Pukul 16.42 